Toronto, Canada

International Symposium on Room Acoustics

2013 June 9-11

\title{
Throw away that standard and listen: your two ears work better
}

Tapio Lokki (tapio.lokki@aalto.fi)

Department of Media Technology

Aalto University School of Science

POBox 15500, FI-00076 Aalto, Espoo, Finland

\begin{abstract}
The acoustics of a concert hall is often described with the help of ISO3382-1:2009 parameters. However, several recent studies suggest that ISO3382-1 cannot explain the details of subjective perception nor preferences of the listeners. The current parameters, averaged over listener positions, and the use of only mid frequencies are definitely inadequate. We have recently measured over 15 concert halls around Europe with a novel measurement system -- the loudspeaker orchestra. It consists of 34 calibrated loudspeakers on stage to simulate an orchestra, the most common sound source in concert halls. For objective analysis and spatial sound reproduction, we measure spatial impulse responses from each loudspeaker at accurately defined receiver positions. This enables accurate comparison of the properties of spatial impulse responses between halls. Furthermore, we have developed methods to convolve anechoic symphony orchestra recordings with the measured spatial impulse responses for multichannel loudspeaker listening. Both subjective comparison of halls and objective analysis with time-frequency and spatiotemporal properties of impulse responses have helped us to link architectural features and subjective perceptions. This presentation will explain these links and their relationship to properties of binaural hearing. Several examples are given to highlight the differences between vineyard and shoe-box type concert halls. In particular, the extreme importance of early reflections for engaging sound is explained.
\end{abstract}

\section{INTRODUCTION}

The acoustics of concert halls and rooms have been investigated for over 100 years. Since the pioneering work of Sabine ${ }^{1}$, scientists have strived to understand why some concert halls sound better than others and what perceptual attributes contribute to the general opinion of extraordinary acoustics. In order to understand human response to the complex sound field in an enclosed space, research on room acoustics has applied both objective and subjective methods ${ }^{2}$.

Subjective comparison of concert halls is not an easy task, because preferred acoustics depends on a large number of elements. The music, the conductor, and the performance of the orchestra greatly affect the listening experience, and the contribution of the auditorium itself is hard to isolate with subjective surveys. Traditionally, concert hall evaluation research has been implemented with questionnaires ${ }^{3,4,5,6,7,8,9}$, or by comparing recordings or simulations $10,11,12,13,14,15,16$ with attributes that are usually defined by the researchers. The studies made in-situ while listening to a real orchestra have revealed that important perceptual features are loudness, reverberance, and intimacy. Laboratory studies have confirmed these discriminating factors, but the possibility 


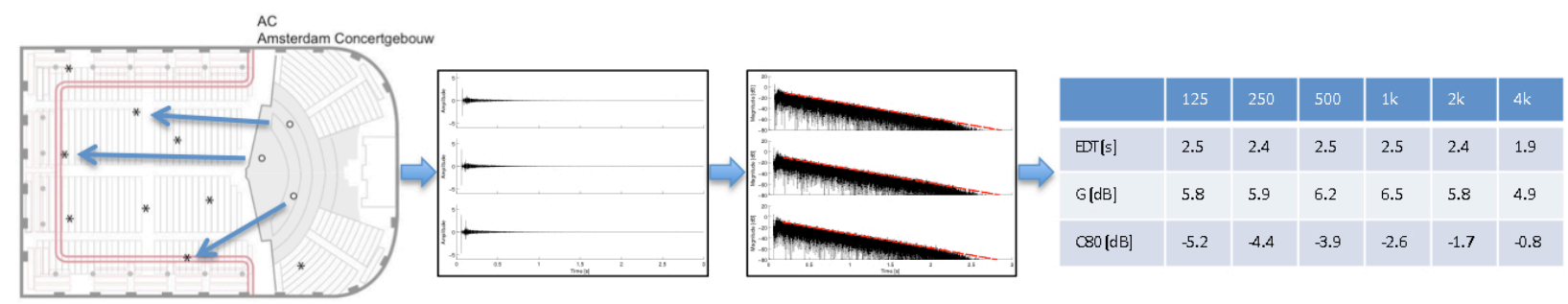

Figure 1: Impulse response measurements from a few source positions to 6-10 receiver positions are the basis for the objective measurements in a concert hall. The room acoustical parameters (ISO3382-1:2009), such as early decay time (EDT) or clarity (C80) are presented as spatial averages of values derived from the decay of the sound pressure level.

for instant comparison inherent in the test conditions helped subjects to also hear differences in clarity, openness, spaciousness, and timbre. However, spatial sound rendering in the laboratory, while suitable for comparative judgments, has not been at the level of authentic reproduction of the original sound environment, thus the spatial sound quality of these investigations have room for improvement. Moreover, despite numerous earlier studies, concert hall acoustics and human perception of sound in such spaces are not yet understood in all aspects.

A few years ago, the ambivalent interpretation of interviews done in-situ in concert halls and the methodological problems of traditional listening tests in laboratories made us rethink the whole subjective evaluation process. We borrowed a sensory evaluation methodology from the food and wine industry ${ }^{17}$; wine tasting shares similar problems with acoustics, such as multidimensional perceptual attributes and matters of personal taste. The sensory evaluation process requires that listeners are able to compare concert halls in the blink of an eye. Therefore, to capture the sound of the same symphony orchestra in every hall we invented a novel concept to simulate a symphony orchestra in real halls: a loudspeaker orchestra ${ }^{18}$. The loudspeakers reproduce anechoic symphony orchestra recordings ${ }^{19}$, and recordings at different seats are made with multi-microphone techniques. In our recent studies, the multi-channel spatial sound rendering has been realized with Directional Audio Coding ${ }^{20,21}$ and with Spatial Impulse Response Rendering ${ }^{22,23}$. Recently we have developed a novel method, the Spatial Decomposition Method, to perform even more authentic spatial sound reproduction in the laboratory ${ }^{24}$. With multichannel 3D sound rendering techniques, concert halls can be accurately compared and sensory evaluation methods have been used to extract the perceptual differences between concert halls ${ }^{25,26}$. Moreover, the preference ratings have been tentatively linked to the sensory profiles to explain the perceptual features behind preferred acoustics.

\section{OBJECTIVE MEASUREMENTS OF CONCERT HALLS}

As the subjective comparison of concert halls is difficult and often biased by matters of taste, researchers have tried to invent objective ways to measure some features of the acoustics. This work has lead to the definition of acoustic parameters described in the international standard ISO3382$1: 2009^{27}$, illustrated in Figure 1. The standard requires that room impulse responses should be measured with an omnidirectional loudspeaker from a few source positions on the stage to 6-10 receiver positions in the audience area. The capturing microphone has omni or figure-of-eight directivity. The parameters are computed from the sound energy decays at different frequency bands.

The ISO3382-1:2009 standard has been criticized from many angles ${ }^{28,29}$. For example, the algorithms to compute the parameters are imprecise, the applied frequency range is inadequate, and a 


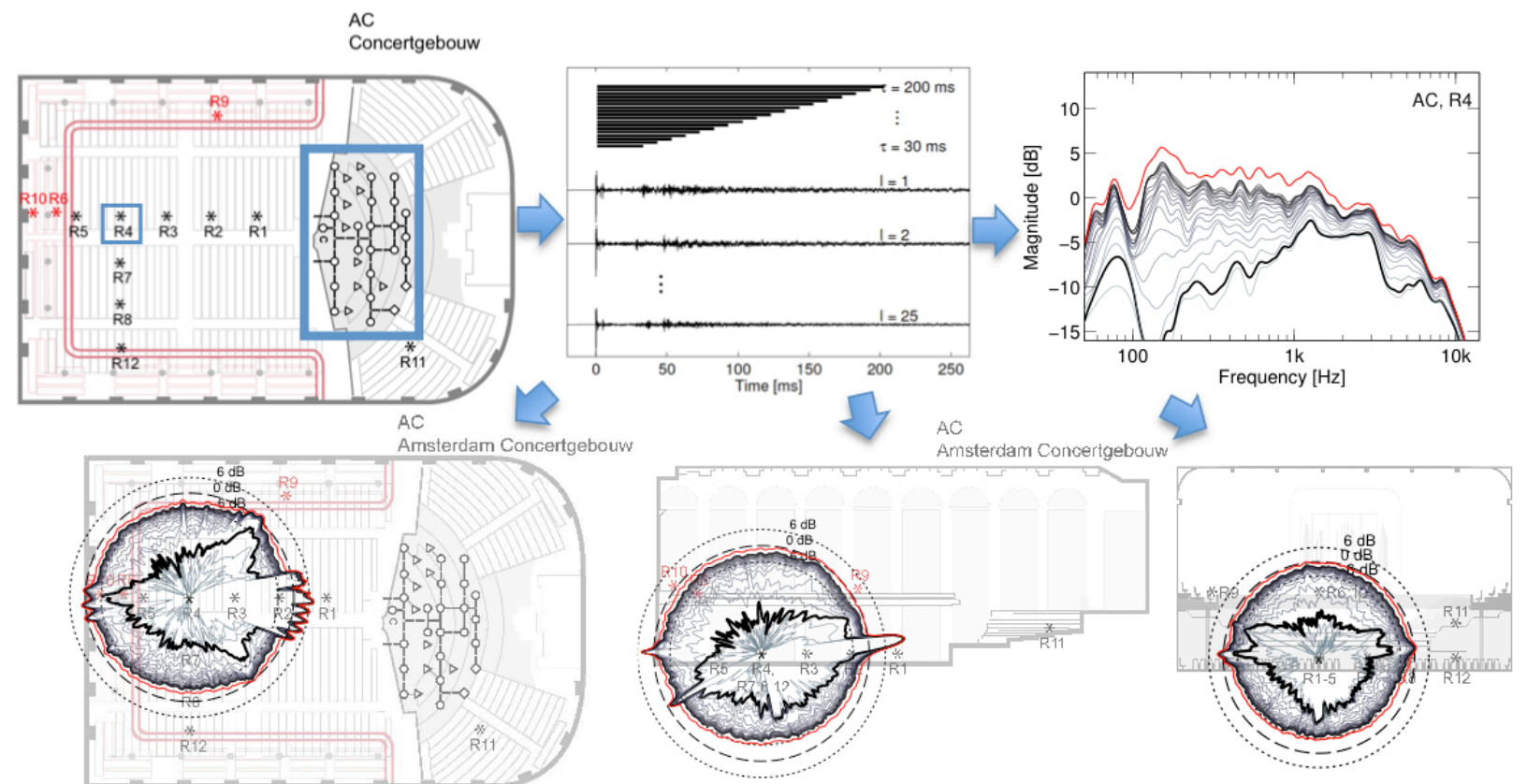

Figure 2: Our approach is to use 34 loudspeakers, which form 25 source channels, and capture spatial impulse responses with a microphone array in one receiver position at a time. The objective analysis is done individually for each response and averages of time-frequency and time-space analyses are plotted to visualize how sound field evolves in temporal, frequency, and spatial domains $^{30}$.

single omnidirectional source does not correspond to real orchestra, which, in reality has dozens of sources with varying directivity characteristics. Moreover, averaging results over several receiver positions hides information as the parameters vary at different distances quite a lot. However, it is generally accepted that some of the standard parameters correlate quite well with subjective perceptions, e.g. Strength (G) with loudness and early decay time (EDT) with reverberance. In contrast, other perceptually relevant factors, e.g., intimacy, have no corresponding objective parameter and values for parameters that correlate with subjective preference judgements are very cumbersome to define.

In order to overcome the inherent simplifications in standard ISO parameters, we have recently taken a novel approach to measure concert hall acoustics, illustrated in Figure 2. The sound source is the same loudspeaker orchestra used to simulate symphony orchestra for subjective studies. The directivities of the loudspeakers differ from the directivities of real instruments, but we have tried to minimize the possible errors by choosing appropriate loudspeakers ${ }^{18}$. The spatial impulse responses for objective analysis from all source positions are captured with a microphone array, currently with six omnidirectional microphones. We have developed a spatial decomposition technique (SDM) ${ }^{24}$ to analyze the spatial distribution of sound energy from every source loudspeaker. Moreover, new time-frequency and spatiotemporal visualization techniques allow examination of sound energy levels in many dimensions: time, frequency, and space (azimuth and elevation). Our recent article ${ }^{30}$ proposes initial ideas to link the development of the spatial sound field over time to the plan and section drawings of the measured concert halls (Figure 2).

Figure 2 is an example analysis of the spatial impulse responses of Concertgebouw, Amsterdam when the receiver position is 19 meters from the closest loudspeakers on stage. The timefrequency plot on the top right shows how the frequency response (average of all 25 source chan- 
nels) evolves in time. The black thick line shows that after $30 \mathrm{~ms}$ there is quite deep dip between 100 and $200 \mathrm{~Hz}$, the well known seat dip caused by diffracted and delayed copy of the direct sound $^{31,32}$. However, at $70 \mathrm{~ms}$ after the direct sound the frequency response is already quite flat and after that sound energy grows gradually. After $200 \mathrm{~ms}$ (last grey line, the red line is the final response) the energy still grows at all frequencies few $\mathrm{dBs}$ indicating nice and audible reverberation. When looking at the spatial distribution of the sound energy (again averaged over all source channels), it can be seen on the bottom left that the first $30 \mathrm{~ms}$ forms a triangular shape with clearly separated direct sounds. Thus, two reflections from side walls indicate fast lateral reflections giving strength to the direct sound and nice frontal sound image with good auditory source width. Again, the sound energy grows gradually in all directions suggesting good and smooth envelopment, even behind the listener. The final response (red curve) is round and stays some dBs below dashed circle, which indicates energy of sources in free field at 10 meters (normalization that is used in ISO parameter Strength, $G$ ). The middle figure on the bottom row shows sound energy distribution on section. It can be seen that no strong ceiling reflection is present from any direction. In addition, the thick $30 \mathrm{~ms}$ curve shows quite a lot of energy reaching the microphones below, see also the rightmost plot showing sound energy in transverse plane. This early energy below causes the seat dip effect. In transverse plane the thick $30 \mathrm{~ms}$ curve shows also that there are indeed four lateral early reflections, two from side walls and two under balcony reflections. Finally, the spatial distribution of reverberation is uniform and the final level is quite high.

\section{CONCERT HALLS MEASURED WITH THE LOUDSPEAKER ORCHESTRA}

So far we have measured 19 concert halls with our loudspeaker orchestra. Nine of them are in Finland and 10 central European halls were measured in November 2012 33,34 . All data have not been analyzed yet and so far we have studied only the Finnish halls with listening tests using sensory evaluation methods ${ }^{25,26}$. These studies have already revealed a lot of novel information on the discriminating subjective attributes that can be used to describe aural differences between halls and how different people compare the halls ${ }^{35}$. In addition, the results made us study detailed properties of reflections and we found that early reflections from diffusors might lower the sound quality ${ }^{36}$ and lateral reflections are preferred as they are perceived louder than median plane reflections due to the shape of the human head ${ }^{37}$. However, much more work is still needed to find all links between architecture of concert halls and the perceived sound and room acoustics quality.

Most people prefer the acoustics that renders the sound of an orchestra intimate and close, with good clarity and openness and the most importantly the sound has to be loud enough and envelop the listener. To render open sound with large dynamics with full spectrum the concert hall has to create quite strong early lateral reflections with full bandwidth ${ }^{37,38}$, hopefully from surfaces that do not modify the phases of different frequency components ${ }^{36}$. Moreover, the early lateral wideband reflections seem to correct the seat dip resulting in strong perceived bass ${ }^{30}$. Finally, the ingredients of engaging sound are large dynamics, proximity, envelopment, flat and rich frequency response and finally slightly emphasized bass to give warmth to the sound.

Although we have not yet studied the famous European concert halls with formal listening tests, some example cases are presented here. A few interesting seats are analyzed with the novel spatiotemporal visualization technique ${ }^{30}$ (see Figure 2).

\subsection{Examples of the different sounding seats around Europe}

Figure 2 already showed the sound distribution in one of the best seats in Europe. Very similar sound energy distribution can be found, e.g., in Musikverein, Vienna and Stadthalle, Wuppertal, see Figure 3. All these visualizations show strong enough direct sounds, clearly visible lateral 


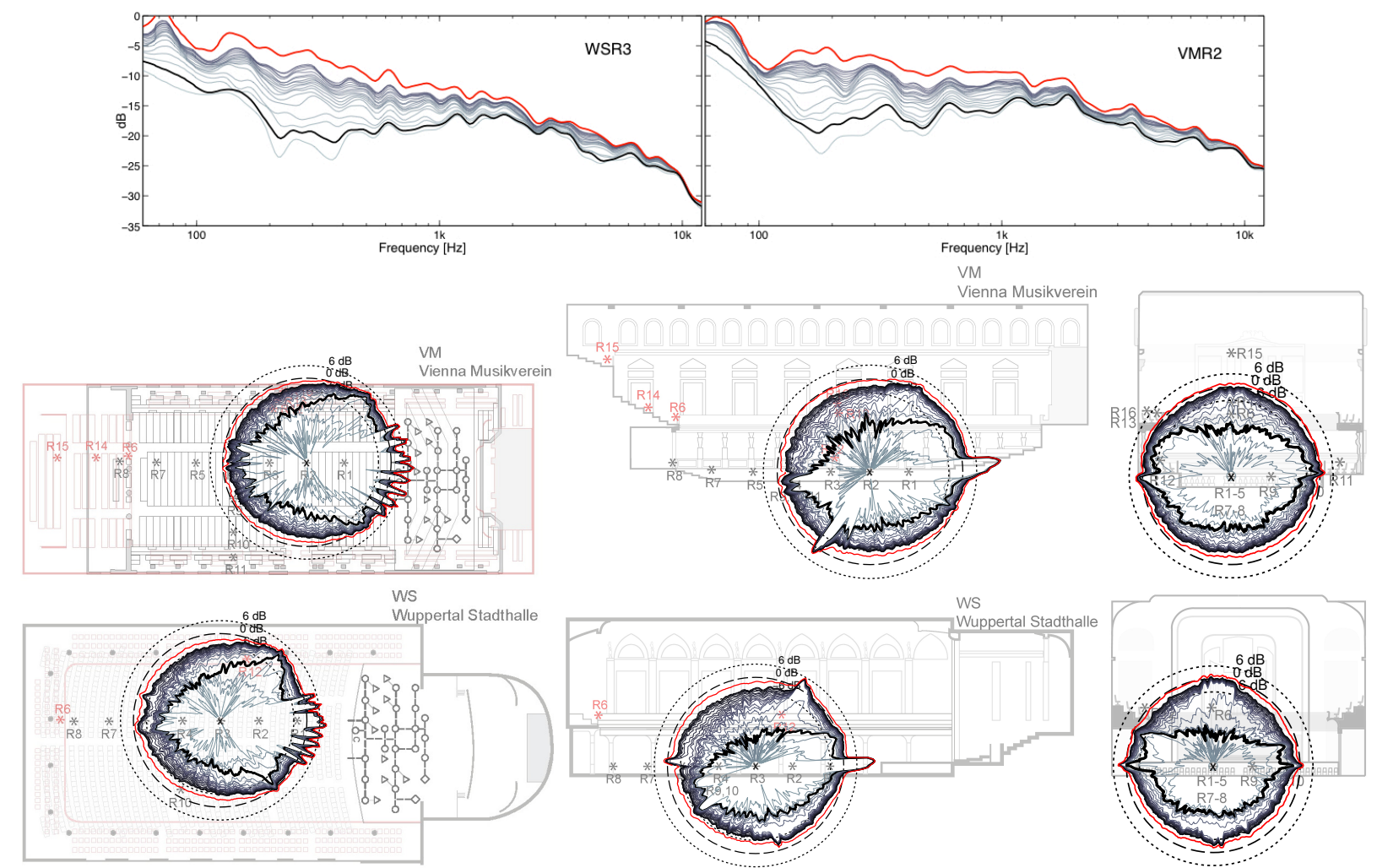

Figure 3: Spatial distribution of sound energy in Vienna Musikverein at the distance of 11 meters and Wuppertal Stadthalle at 15 meters from the loudspeaker orchestra.

early reflections, hardly any strong ceiling reflections, very good envelopment and enough sound power. The visualizations of changes in frequency responses tell about the frequency balance and timbre of sound, and indeed all these three seats (in Figs. 2-3) have slightly different sound color. However, all of them have enough/strong bass and a lot of high frequencies resulting in warm sound with good envelopment and openness.

It is not a surprise that the best seat examples are from shoe-box halls. Those halls also have a flat floor on the audience area enabling nice enveloping reverberation. If the audience area is strongly inclined the seats behind block the enveloping reverberation. This is quite well seen in the directional analyses shown in Figure 4. Moreover, due to the lack of the side reflections the thick $30 \mathrm{~ms}$ curve is oval and the final energy (red curve) is not round. In Berlin Philharmonie there are quite late side reflections that might be perceived as echoes. The section plots show nicely the ceiling reflections typical to these geometries. In Cologne Philharmonie the far back wall of the hall reflects energy that reaches the listening position very late, making the perceived sound image even more monophonic.

The final examples are from two vineyard type halls, seats on the side or behind the orchestra, see Figure 5. Such seats have obvious balance problems between instrument sections and loss of high frequencies due to the directivity of instruments ${ }^{39}$. The lack of early lateral reflection is clearly seen and the envelopment is also very weak. Moreover, even though the seats are quite close to the stage the overall sound power is weak. The section plots show strong and quite late ceiling reflections that might result, together with attenuated high frequencies, in a too distant sound image. 


\section{FINAL REMARKS}

The purpose of art, including acoustic music presented in a concert hall, is to bring joy to everyday life and tell stories. The composers try to convey their ideas, feelings, imagination, emotions, etc. with the help of musicians, to the listeners. Therefore, the concert hall has to support musicians in their work and it needs to carry the music from the stage to the audience with full spectrum and dynamics. The concert hall as a medium for sound propagation is a linear system, while the dynamics of music and human binaural hearing are non-linear in many ways ${ }^{40}$. The objective means to measure acoustics are based on impulse responses and parameters derived from them, which is physically correct as the hall is a linear system. However, the interpretation of those parameters should be revised to take into account the non-linearities of music dynamics and human hearing. For example, just noticeable differences of objective parameters should be frequency dependent to understand better the acoustics of concert halls.

\section{ACKNOWLEDGMENTS}

I like to thank the whole Virtual Acoustics team for the hard work that has led to the results presented here. The research leading to these results has received funding from the Academy of Finland, project nos. [119092, 257099] and the European Research Council under the European Community's Seventh Framework Programme (FP7/2007-2013) / ERC grant agreement no. [203636].

\section{REFERENCES}

1 W.C. Sabine. Reverberation: Introduction. The American Architect, 1900.

2 L. Beranek. Concert Halls and Opera Houses: Music, Acoustics, and Architecture. SpringerVerlag (New York), 2nd edition, 2004. 664 pages.

3 R.J. Hawkes and H. Douglas. Subjective acoustics experience in concert auditoria. Acustica, 24:235--250, 1971.

4 M. Barron. Subjective study of british symphony concert halls. Acustica, 66:1--14, 1988.

5 E. Kahle. Validation d'un modèle objectif de la perception de la qualité acoustique dans un ensemble de salles de concerts et d'opéras. PhD thesis, Université du Maine, Le Mans, 1995.

6 A.G. Sotiropoulou, R.J. Hawkes, and D.B. Fleming. Concert hall acoustic evaluations by ordinary concert-goers: I, Multi-dimensional description of evaluations. Acustica, 81(1):1--9, 1995.

7 A.G. Sotiropoulou and D.B. Fleming. Concert hall acoustic evaluations by ordinary concertgoers: II, Physical room acoustic criteria subjectively significant. Acustica, 81(1):10--19, 1995.

8 L. Beranek. Concert and Opera Halls --- How They Sound. Acoustical Society of America, New York, NY, USA, 1996.

9 A. Giménez, R. M. Cibrian, and S. Cerda. Subjective assessment of concert halls: a common vocabulary for music lovers and acousticians. Archives of Acoustics, 37(3):331--340, 2012.

10 M.R. Schroeder, G. Gottlob, and K.F. Siebrasse. Comparative study of european concert halls: Correlation of subjective preference with geometric and acoustics parameters. Journal of the Acoustical Society of America, 56(4):1195--1201, October 1974.

11 G.A. Soulodre and J.S. Bradley. Subjective evaluation of new room acoustic measures. Journal of the Acoustical Society of America, 98(1):294--301, July 1995.

12 O. Warusfel, C. Lavandier, and J.P. Jullien. Perception of coloration and spatial effects in room acoustics. In Proc. 13th Int. Congr. Acoust. (ICA'89), pages 173--176, Belgrade, Yugoslavia, July 1989.

13 C. Lavandier. Validation perceptive d'un modèle objectif de caractérisation de la qualité acoustique des salles. PhD thesis, Université du Maine, Le Mans, 1989. 
14 J.S. Bradley and G.A. Soulodre. Objective measures of listener envelopment. Journal of the Acoustical Society of America, 98(5):2590--2597, 1995.

15 Y. J. Choi and F. R. Fricke. A comparison of subjective assessments of recorded music and computer simulated auralizations in two auditoria. Acta Acustica united with Acustica, 92(4):604--611, 2006.

16 J. Pätynen and T. Lokki. Evaluation of concert hall auralization with virtual symphony orchestra. Journal of Building Acoustics, 18(3-4):349--366, 2011.

17 H.T. Lawless and H. Heymann. Sensory evaluation of food: principles and practices. Aspen Publishers, New York, NY, USA, 1999. 827 pages.

18 J. Pätynen. A Virtual Symphony Orchestra for Studies on Concert Hall Acoustics. PhD thesis, Aalto University School of Science, 2011.

19 J. Pätynen, V. Pulkki, and T. Lokki. Anechoic recording system for symphony orchestra. Acta Acustica united with Acustica, 94(6):856--865, November/December 2008.

20 V. Pulkki. Spatial sound reproduction with directional audio coding. Journal of the Audio Engineering Society, 55(6):503--516, 2007.

21 J. Vilkamo, T. Lokki, and V. Pulkki. Directional audio coding: Virtual microphone based synthesis and subjective evaluation. Journal of the Audio Engineering Society, 57(9):709--724, September 2009.

22 J. Merimaa and V. Pulkki. Spatial impulse response rendering I: Analysis and synthesis. Journal of the Audio Engineering Society, 53(12):1115--1127, 2005.

23 V. Pulkki and J. Merimaa. Spatial impulse response rendering II: Reproduction of diffuse sound and listening tests. Journal of the Audio Engineering Society, 54(1):3--20, 2006.

24 S. Tervo, J. Pätynen, A. Kuusinen, and T. Lokki. Spatial decomposition method for room impulse responses. Journal of the Audio Engineering Society, 61(1/2):16--27, January/February 2013.

25 T. Lokki, J. Pätynen, A. Kuusinen, H. Vertanen, and S. Tervo. Concert hall acoustics assessment with individually elicited attributes. Journal of the Acoustical Society of America, 130(2):835--849, August 2011.

26 T. Lokki, J. Pätynen, A. Kuusinen, and S. Tervo. Disentangling preference ratings of concert hall acoustics using subjective sensory profiles. Journal of the Acoustical Society of America, 132(5), November 2012. 3148-3161.

27 ISO 3382-1. Acoustics -- measurement of room acoustic parameters -- part 1: Performance spaces. International Standards Organization, 2009.

28 J.S. Bradley. Review of objective room acoustics measures and future needs. Applied Acoustics, 72:713--720, 2011.

29 L. Kirkegaard and T. Gulsrud. In search of a new paradigm: How do our parameters and measurement techniques constrain approaches to concert hall design? Acoustics Today, 7(1):7--14, 2011.

30 J. Pätynen, S. Tervo, and T. Lokki. Analysis of concert hall acoustics via visualizations of time-frequency and spatiotemporal responses. Journal of the Acoustical Society of America, 133(2):842--857, February 2013.

31 T.J. Schultz and B.G. Watters. Propagation of sound across audience seating. Journal of the Acoustical Society of America, 36(5):885--896, 1964.

32 G.M. Sessler and J.E. West. Sound transmission over theatre seats. Journal of the Acoustical Society of America, 36(9):1725--1732, 1964.

33 T. Lokki. Sensory evaluation of concert hall acoustics. In the 21st International Congress on Acoustics (ICA'2013), Montreal, Canada, June 2-7 2013. Plenary lecture.

34 S. Tervo, J. Pätynen, and T. Lokki. Spatial analysis of concert hall impulse responses. In 
International Symposium on Room Acoustics (ISRA 2013), Toronto, Canada, June 9-11 2013.

35 A. Kuusinen and T. Lokki. Individual differences in quality judgments and preferences of concert hall acoustics. In International Symposium on Room Acoustics (ISRA 2013), Toronto, Canada, June 9-11 2013.

36 T. Lokki, J. Pätynen, S. Tervo, S. Siltanen, and L. Savioja. Engaging concert hall acoustics is made up of temporal envelope preserving reflections. Journal of the Acoustical Society of America, 129(6):EL223--EL228, June 2011.

37 T. Lokki and J. Pätynen. Lateral reflections are favorable in concert halls due to binaural loudness. Journal of the Acoustical Society of America, 130(5):EL345--EL351, 2011.

38 J. Blauert and W. Lindemann. Auditory spaciousness: Some further psychoacoustic analyses. Journal of the Acoustical Society of America, 80(2):533--542, 1986.

39 J. Pätynen and T. Lokki. Directivities of symphony orchestra instruments. Acta Acustica united with Acustica, 96(1):138--167, January/February 2010.

40 J. Pätynen, S. Tervo, and T. Lokki. Binaural dynamic responsiveness in concert halls. In International Symposium on Room Acoustics (ISRA 2013), Toronto, Canada, June 9-11 2013. 


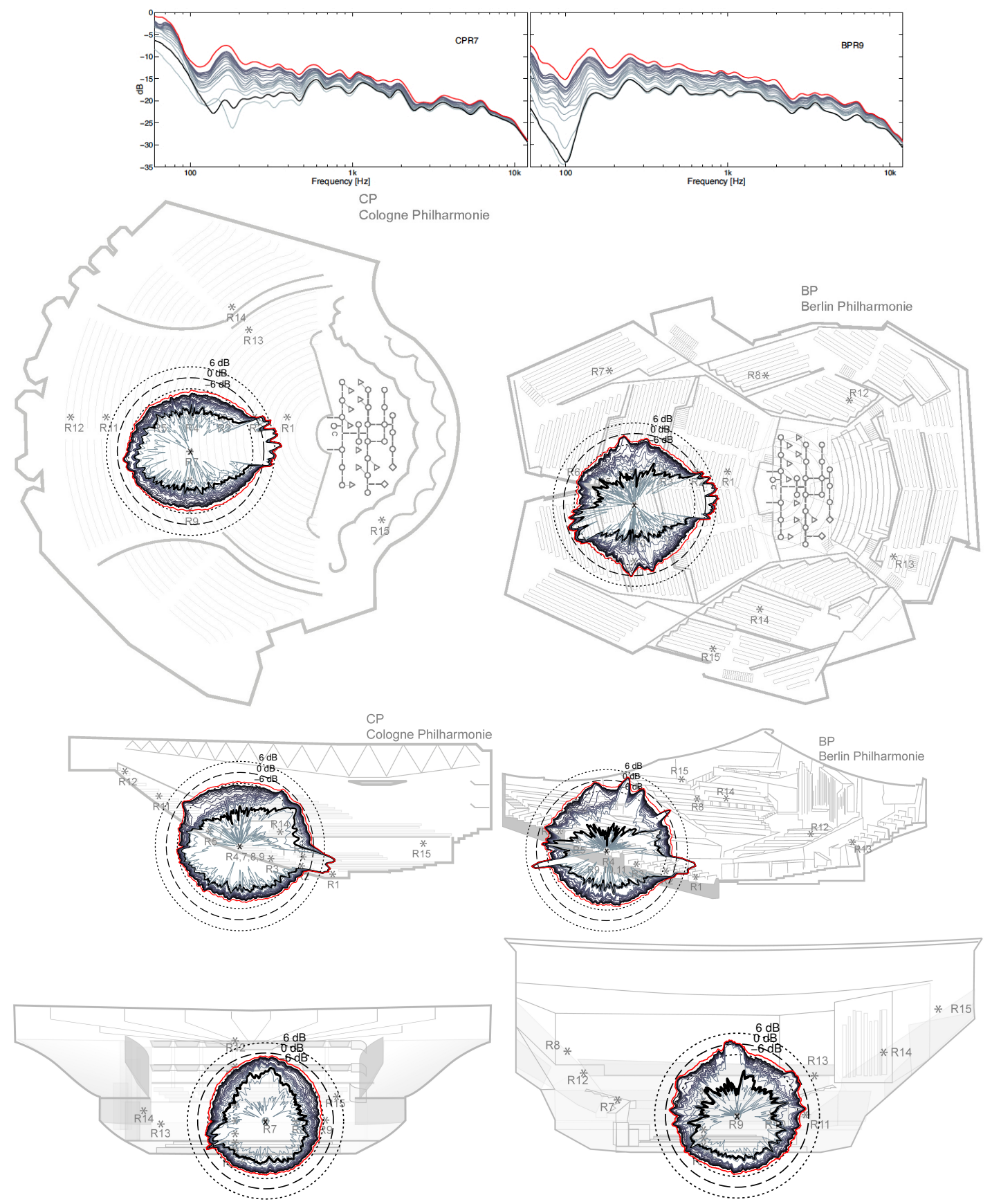

Figure 4: Spatial distribution of sound energy in Cologne Philharmonie and Berlin Philharmonie. 

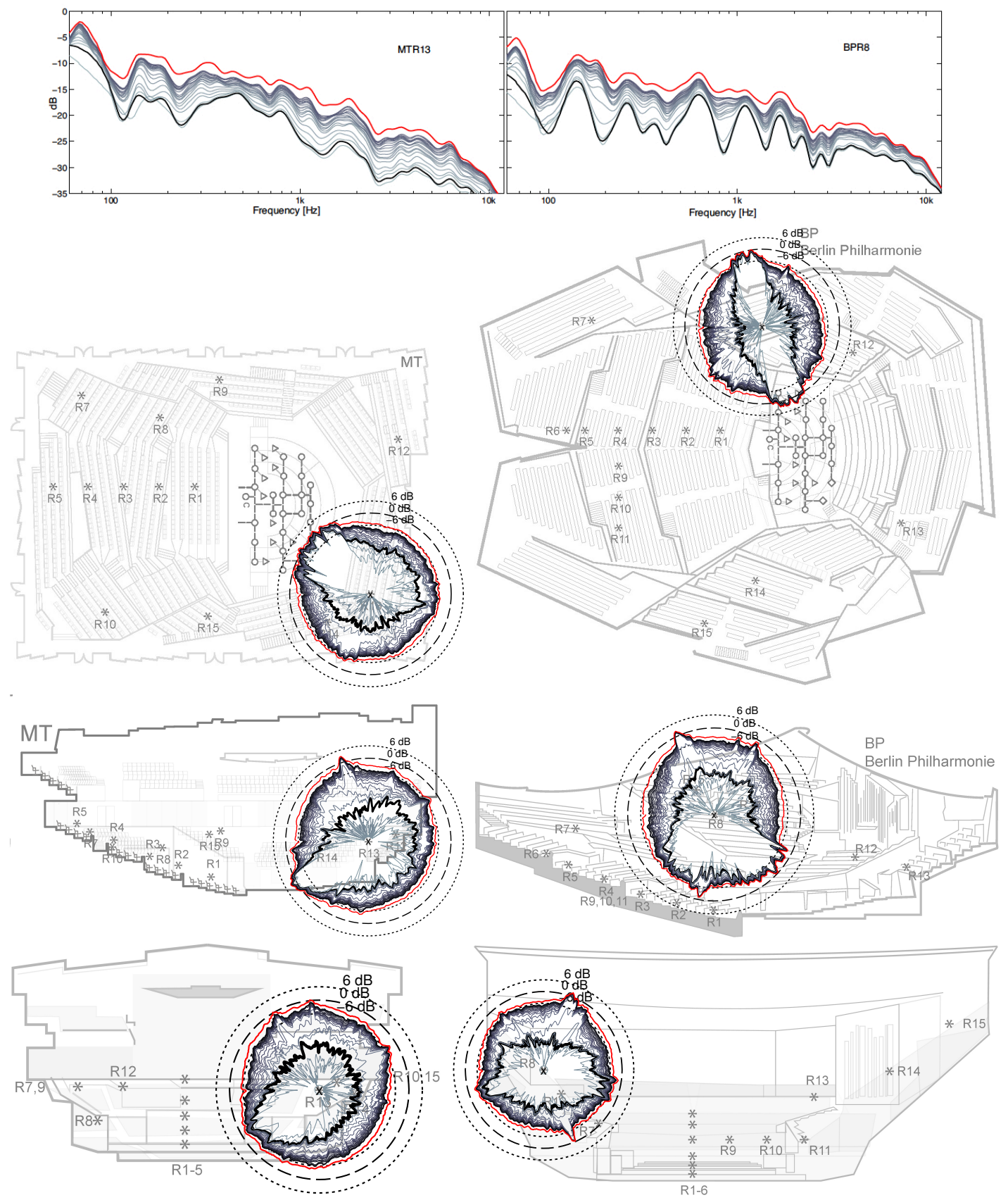

Figure 5: Spatial distribution of sound energy close to the orchestra on the side audience sections in Helsinki Music Center and Berlin Philharmonie. 